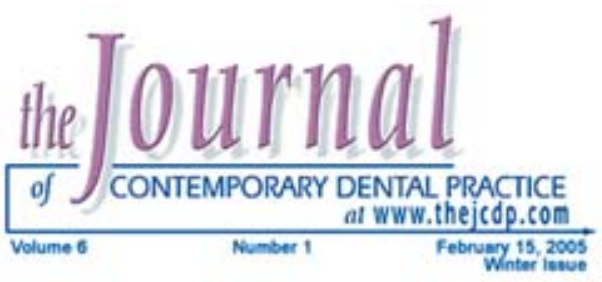

\title{
Emotional Effects of Malocclusion in Nigerian Orthodontic Patients
}

\author{
Chukwudi O. Onyeaso, BDS, FWACS; Ifeoma L. Utomi, BDS, FWACS; \\ Titus S. Ibekwe, MBBS
}

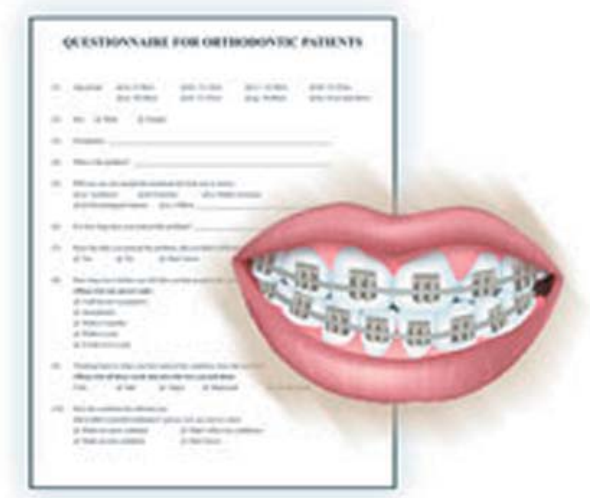

\section{Abstract}

Aim: To assess the emotional effects of malocclusion among Nigerian orthodontic patients.

Design: A questionnaire survey.

Subjects and Methods: A questionnaire was completed by 221 Nigerian orthodontic patients undergoing routine orthodontic care at the Orthodontic Unit, Department of Preventive Dentistry, University College Hospital, Ibadan and the Department of Child Dental Health, Lagos University Teaching Hospital, Lagos, both in South-West Nigeria. The participants were comprised of $97(43 \%)$ males and $124(56.1 \%)$ females with age range of $6-40$ years (mean age, $13.82 \pm 8.01 \mathrm{SD}$ ). Data were analyzed using descriptive statistics and Chi-square test.

Results: About $44 \%$ of all participants had not yet accepted their malocclusions, while $56.6 \%$ of all subjects reported for orthodontic care due to aesthetic reasons. Twenty-seven percent of the subjects were depressed the first time they notice their malocclusions. Over $40 \%$ of the participants reported feeling less confident as a result of their malocclusions and about $55 \%$ of them felt their malocclusions negatively affected their general

(C) Seer Publishing 
facial appearances. Normal activities restricted in some of the subjects due to malocclusion included laughing in public $(48.9 \%)$, meeting people in public $(32 \%)$, and forming close relationships $(20.4 \%)$. The majority $(64.7 \%)$ of the subjects discussed their malocclusions with their parents, followed by dentists $(35.3 \%)$.

Conclusion: The psychosocial effects of malocclusion in Nigerian orthodontic patients were considerable with no significant gender differences. Considering such factors, professional counseling of Nigerian orthodontic patients is encouraged.

Keywords: Malocclusion, psychosocial effects, Nigerian orthodontic patients

Citation: Onyeaso CO, Utomi IL, Ibekwe TS. Emotional Effects of Malocclusion in Nigerian Orthodontic Patients. J Contemp Dent Pract 2005 February;(6)1:064-073.

\section{Introduction}

Professional assessment of the need for orthodontic treatment implies considerations to whether the malocclusion has or will have adverse effects on the oral health and/or the social or psychological well being of the individual. ${ }^{1}$ The motivation to seek orthodontic treatment appears to be strongly related to the individual's perceptions of the extent to which their dental facial appearance deviates from sociocultural norms. ${ }^{2-4}$

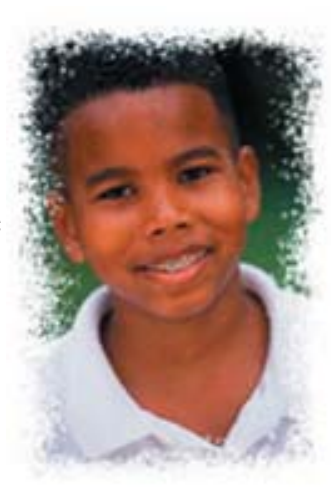

A person's response to dental facial attractiveness can be viewed as a type of psychosocial response to occlusal status ${ }^{5}$ and as such have a cultural emphasis. ${ }^{2}$ There is a body of opinion that an individual's level of satisfaction with their facial appearance may have important implications for their self esteem., 6-11 Although there are substantial reports on social or psychosocial aspects of malocclusion among the population of the industrialized parts of the globe, there has been little in the way of systematic study of the area to shed light on the actual effects of malocclusion on the individual's perception of self. ${ }^{12}$ In an American study ${ }^{13}$ demonstrable differences were found in body-image and self-concept satisfaction between a prospective orthodontic patient sample, a treated group, and a general population sample.

In a carefully structured investigation Sergl and Stodt ${ }^{14}$ found that minor variation in tooth positions could be a significant determinant for the overall aesthetic impression of a face. The teeth also seem to be an important target for teasing and ridicule among school children, $7 \%$ of whom were teased about their teeth once per week or more in the study of Sergl and Stodt. ${ }^{14}$ Research with children indicates physical appearance is important in biasing judgments of social acceptability, ability and person ability, and whether the judges are adults or other children. ${ }^{15-17}$ Children themselves see peers who are physically attractive as more socially attractive $e^{18-20}$, and unattractive children are more likely to be the victims of bullying ${ }^{21}$ In deed unacceptable dental appearance including deviant dental characteristics are a phenomena that may affect many facets of social interaction including career advancement, peer group acceptance, and negative effect on self concept. ${ }^{22-24}$

Nigeria is the most populous black nation in the world today with well over 120 million people. Ibadan City is the capital of Oyo State in Nigeria and the largest city in the southern Sahara, while Lagos is the most populated city in Nigeria and a major economic nerve centre in the country. The practice and teaching of orthodontics started at the Lagos University Teaching Hospital (LUTH), Idi-araba, Lagos. Dental centre, University College Hospital, Ibadan, Nigeria and the Dental centre, Lagos University Teaching hospital (LUTH), Lagos, Nigeria, are among the major referral centres for orthodontic care in Nigeria.

Knowledge about orthodontic patients' psychosocial or emotional reactions to malocclusion in Nigeria could be helpful in 
effective professional counseling and treatment of patients within the Nigerian context; therefore, the aim of this study was to assess the psychosocial or emotional effects of malocclusion among orthodontic patients in Nigeria.

\section{Materials and Methods}

A survey was conducted of patients attending the orthodontic clinics in two teaching hospitals in Nigeria: University College Hospital, Ibadan and Lagos University Teaching Hospital, Lagos, both in South-West Nigeria.

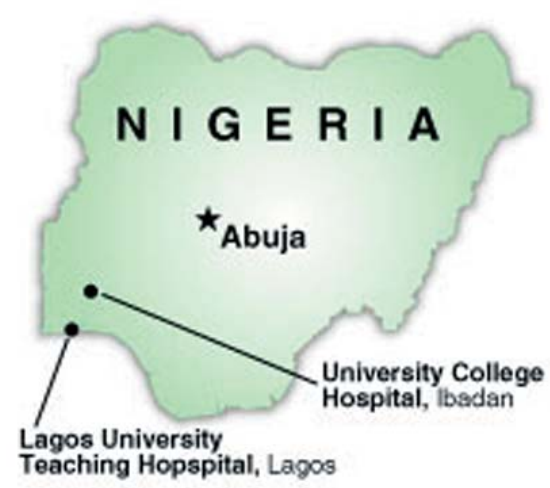

A pre-tested, 15-item questionnaire (Figure 1) modified from the work of Fiske et al. ${ }^{25}$ to elucidate psychosocial or emotional effects of malocclusion in orthodontic patients was administered to 221 consecutive patients. The subjects consisted of 97 (43.9\%) males and $124(56.1 \%)$ females with age range of 6-40 and mean age of $13.82 \pm 8.01(\mathrm{SD})$ years, respectively.

Questionnaires were distributed and collected in accordance with the guidelines recommended by Gosney. ${ }^{26}$ To eliminate biased responses from the subjects, the replies were anonymous. All the patients who came for treatment or were already receiving treatment between March and September, 2003 who were willing to participate in the study were included.

\section{Statistical Analysis}

The data were analyzed using descriptive statistics (frequency distribution, percentage ratio for each of the variables, mean age, and standard deviation), while chi-square tests were used to test for gender differences with the variables. The critical level of statistical significance was set at $P<0.05$. All analyses were done using statistical package for social sciences (SPSS for MS WINDOWS Release 6.0).

\section{Results}

The age and gender distribution of the patients is shown in Table 1 with well over half of them belonging to age 15 years and below. More females sought orthodontic treatment than males.

The majority of subjects needed orthodontic care for aesthetics $(56.6 \%)$. Functional reasons accounted for $12.2 \%$, while psychological reasons gave $10.0 \%$ as shown in Table 2 .

Table 3 shows the distribution of the time taken to accept the malocclusion by the subjects with the majority (44.3\%) yet to accept their malocclusions. No statistically significant $(p>0.05)$ gender differences were observed.

With regard to confidence, over $40 \%$ of the participants reported feeling less confident as a result of malocclusion, while $2.7 \%$ claimed they felt more confident. Close to $40 \%$ claimed no difference in confidence as shown in Table 4. Thinking back on their initial feelings when they first noticed the malocclusions, $34.4 \%$ said they felt sad, $6.3 \%$ were angry, $26.7 \%$ had depression, and $35.3 \%$ were unconcerned.

Regarding confidence, $23.1 \%$ reported having less confidence eating in public, while $3.6 \%$ and $73.3 \%$ indicated feeling more confident and no difference in confidence, respectively. Over 32\% felt less confident meeting people publically, 5.4\% claimed feeling more confident, and $62.0 \%$ said it did not make any difference. Laughing in the public was a problem for $48.9 \%$, while $5.9 \%$ and $45.2 \%$ claimed feeling more confident and no difference in confidence, respectively. About $20.4 \%$ felt less confident to form close relationships, $6.3 \%$ felt more confident, and $73.3 \%$ said they experienced no difference.

Table 5 shows the distribution of activities restricted due to malocclusion as reported by the subjects. Laughing in public was mostly affected $(47.1 \%)$. 
Figure 1.

\section{QUESTIONNAIRE FOR ORTHODONTIC PATIENTS}

(1)

Age group:

$\square$ (a) 6-10yrs

$\square$ (b) $11-15 \mathrm{yrs}$

$\square$ (c ) $16-20 \mathrm{yrs}$

(d) $21-25 \mathrm{yrs}$

$\square$ (e) 26-30yrs

$\square$ (f) 31-35yrs

$\square(\mathrm{g}) 36-40 \mathrm{yrs}$

$\square$ (h) 41yrs and above

(2) Sex: $\sqcup$ Male $\sqcup$ Female

(3) Occupation:

(4) What is the problem?

(5) Will you say you needed the treatment for (tick one or more)
$\square$ (a) Aesthetics
$\square$ (b) Function
$\square(\mathrm{c})$ Stable occlusion

$\square(\mathrm{d})$ Psychological reasons $\quad \square(\mathrm{c})$ Others

(6) For how long have you noticed the problem?

(7) Since the time you noticed the problem, did you find it difficult to accept the condition?

口 Yes a No $\square$ Don't know

(8) How long was it before you felt that you had accepted the condition?

(Please tick one answer only)

I still haven't accepted it

Immediately

- Within 6 months

$\square$ Within a year

It took over a year

(9) Thinking back to when you first noticed the condition, how did you feel?

(Please tick all those words that describe how you felt them)

I felt... $\sqcup \mathrm{Sad} \sqcup \sqcup$ Angry $\sqcup$ Depressed

(10) How the condition has affected you

Did it affect yourself-confidence? (please tick one answer only)

$\square$ Made me more confident

$\square$ Didn't affect my confidence

a Made me less confident

Don't know 
Table 1. Age and gender distribution of the subjects.

\begin{tabular}{|c|c|c|c|c|c|c|}
\hline Age groups (years & \multicolumn{5}{|c|}{ Gender } & \multicolumn{2}{c|}{ Total } \\
\hline & \multicolumn{2}{|c|}{ Male } & \multicolumn{2}{|c|}{ Female } & \multicolumn{2}{c|}{} \\
\hline & $\mathrm{n}$ & $\%$ & $\mathrm{n}$ & $\%$ & $\mathrm{n}$ & 38 \\
\hline $6-10$ & 24 & 63.2 & 14 & 36.8 & 77 & 34.2 \\
\hline $11-15$ & 32 & 41.6 & 45 & 58.4 & 46 & 20.8 \\
\hline $16-20$ & 13 & 28.3 & 33 & 71.7 & 35 & 15.8 \\
\hline $21-25$ & 15 & 42.9 & 20 & 57.1 & 21 & 9.5 \\
\hline $26-30$ & 12 & 57.1 & 9 & 42.9 & 3 & 1.4 \\
\hline $31-35$ & 1 & 33.3 & 2 & 66.7 & 1 & 0.5 \\
\hline $36-40$ & - & - & 1 & 100.0 & 100.0 \\
\hline Total & 97 & 43.9 & 124 & 56.1 & 221 & 1 \\
\hline
\end{tabular}

Table 2. Motivating factors in seeking orthodontic care by gender.

\begin{tabular}{|c|c|c|c|c|c|c|}
\hline Motivating factor & \multicolumn{5}{|c|}{ Gender } & \multicolumn{2}{c|}{ Total } \\
\hline & \multicolumn{2}{|c|}{ Male } & \multicolumn{2}{c|}{ Female } & \multicolumn{2}{c|}{$\%$} \\
\hline & $\mathrm{n}$ & $\%$ & $\mathrm{n}$ & $\%$ & $\mathrm{n}$ & 56.6 \\
\hline Aesthetics & 61 & 48.8 & 64 & 51.2 & 125 & 12.2 \\
\hline Function & 9 & 33.3 & 18 & 66.7 & 27 & 10.0 \\
\hline $\begin{array}{c}\text { Psychological } \\
\text { reasons }\end{array}$ & 9 & 40.9 & 13 & 59.1 & 22 & 10.0 \\
\hline Stable Occlusion & 7 & 31.8 & 15 & 68.2 & 22 & 5.3 \\
\hline Other reasons & 3 & 60.0 & 2 & 40.0 & 5 & 9.0 \\
\hline No response & 8 & 40.0 & 12 & 60.0 & 20 & 100.0 \\
\hline Total & 97 & 43.9 & 124 & 56.1 & 221 & \\
\hline
\end{tabular}

$X^{2}=4.48 ;$ df $=5 ; P=0.48^{\star}$ ( ${ }^{\star}$ No statistically significant differences).

Table 3. Distribution of time taken to accept the malocclusion by the subjects in relation to gender.

\begin{tabular}{|c|c|c|c|c|c|c|}
\hline Time taken & \multicolumn{5}{|c|}{ Gender } & \multicolumn{2}{c|}{ Total } \\
\hline & \multicolumn{2}{|c|}{ Male } & \multicolumn{2}{c|}{ Female } & \multicolumn{2}{c|}{} \\
\hline & $\mathrm{n}$ & $\%$ & $\mathrm{n}$ & $\%$ & $\mathrm{n}$ & 28.5 \\
\hline Immediately & 25 & 39.7 & 38 & 60.3 & 63 & 17 \\
\hline Within 6 months & 7 & 41.2 & 10 & 58.8 & 13 & 5.9 \\
\hline Within a year & 8 & 61.5 & 5 & 38.5 & 13 \\
\hline Over a year & 11 & 36.7 & 19 & 63.3 & 30 & 13.6 \\
\hline Still not accepted & 46 & 46.9 & 52 & 53.1 & 98 & 44.3 \\
\hline Total & 97 & 43.9 & 124 & 56.1 & 221 & 100.0 \\
\hline
\end{tabular}

$X^{2}=3.15 ; \mathrm{df}=4 ; \mathrm{P}=0.53^{\star}$ ( ${ }^{\star}$ No statistically significant sex differences). 
Table 4. Distribution of the effects of malocclusion on self-confidence.

\begin{tabular}{|c|c|c|c|c|c|c|}
\hline & \multicolumn{4}{|c|}{ Gender } & \multicolumn{2}{c|}{ Total } \\
\hline & Male & \multicolumn{2}{|c|}{ Female } & $\mathrm{n}$ & $\%$ \\
\hline & $\mathrm{n}$ & $\%$ & $\mathrm{n}$ & $\%$ & 6 & 2.7 \\
\hline More confident & 3 & 3.1 & 3 & 2.4 & & \\
\hline $\begin{array}{c}\text { Confidence } \\
\text { unaffected }\end{array}$ & 4041.2 & 48 & 38.7 & 88 & 39.8 \\
\hline Less confident & 44 & 45.4 & 54 & 43.5 & 98 & 44.3 \\
\hline Uncertain & 10 & 10.3 & 19 & 15.3 & 29 & 13.1 \\
\hline Total & 97 & 43.9 & 124 & 56.1 & 221 & 100.0 \\
\hline
\end{tabular}

$X^{2}=1.26 ; d f=3 ; P=0.74^{\star}\left({ }^{\star}\right.$ No statistically significant sex differences $)$

Table 5. Distribution of activities restricted due to malocclusion as reported by the subjects.

\begin{tabular}{|c|c|c|c|c|c|c|}
\hline Activity & \multicolumn{9}{|c|}{ Effect } \\
\hline & \multicolumn{2}{|c|}{ No res ponse } & \multicolumn{2}{c|}{ Not restricted } & \multicolumn{2}{c|}{ Restricted } \\
\hline & $\mathrm{n}$ & $\%$ & $\mathrm{n}$ & $\%$ & $\mathrm{n}$ & $\%$ \\
\hline Choice of food & 15 & 6.8 & 170 & 76.9 & 36 & 16.3 \\
\hline Eating in public & 18 & 8.1 & 169 & 76.5 & 34 & 15.4 \\
\hline Going out in public & 18 & 8.1 & 191 & 86.4 & 12 & 5.4 \\
\hline Laughing in Public & 10 & 4.5 & 107 & 48.4 & 104 & 47.1 \\
\hline $\begin{array}{c}\text { Forming close } \\
\text { relationship }\end{array}$ & 24 & 10.9 & 168 & 76.0 & 29 & 13.1 \\
\hline $\begin{array}{c}\text { Enjoying food as } \\
\text { much }\end{array}$ & 19 & 8.6 & 173 & 78.3 & 29 & 13.1 \\
\hline
\end{tabular}

Concerning the people the subjects discussed their malocclusions with before coming for treatment, parents had the highest percentage of $64.7 \%$, followed by dentists (35.3\%).

Most of the subjects $(57.5 \%)$ presented for orthodontic care within 1-5 years after noticing the problem, followed by $23.5 \%$ who reported for treatment after 6-10 years of noticing the malocclusion. About $11 \%$ came for care between the ages of $11-15$ years and $1.8 \%$ after 16 years. The remainder $(5.9 \%)$ could not remember the time lapse.

Concerning the perceived effects of malocclusions on the general appearance of their faces, $54.8 \%$ felt their malocclusions affected their faces negatively, while $45.2 \%$ did not think their facial appearances were affected. Close to $40 \%$ of those whose facial appearances were negatively affected said they were displeased, while $6.8 \%$ were upset by such effects.

\section{Discussion}

The psychosocial or emotional handicap imposed by an unaesthetic dental appearance may have a significant impact on individual well-being, particularly for children who are stigmatized or ridiculed by their peers and come to view themselves as inadequate. On the other hand, minor imperfections in dental appearance may be of little real significance and the demand for cosmetic correction is unlikely to bear a simple relationship to the degree of anatomical deviation. ${ }^{12}$

The authors are not aware of any previous report on emotional or psychological effects of malocclusion in the Nigerian population. Although the present data can not be seen as representative of the whole Nigerian population, it gives a good impression of the pattern of psychosocial or emotional effects malocclusions have on real orthodontic patients in Nigeria. Therefore, it could be a 
good guide in the effective management of Nigerian orthodontic patients. This study also has shown that although the majority of the patients were children and adolescents, Nigerian adults are equally showing interest in orthodontic care.

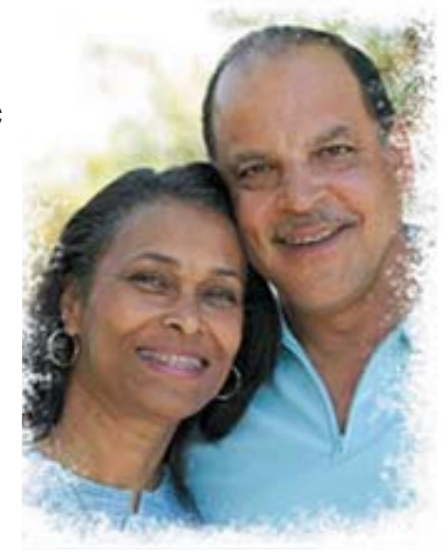

The results of this study showed more females sought orthodontic treatment than males. The higher number of females presenting for orthodontic treatment as observed in this study is consistent with the report of Shaw. ${ }^{27}$ However, it must be noted this is not a reflection of the prevalence and orthodontic treatment need in the general Nigerian population where no significant gender differences have been documented and no gender bias was demonstrated in the parental orthodontic concern. ${ }^{28}$ This observed gender difference in seeking orthodontic care could be a reflection of the discrepancy observed in self-perception of dental appearance among Nigerian adolescents $^{29}$, which influences their desire for orthodontic treatment. This Nigerian situation supports the experience of Ingervall and Hedegard. ${ }^{30}$ In addition the societal expectations and roles of the female gender could also encourage more females in Nigeria to seek orthodontic care for aesthetic and psychosocial reasons. This Nigerian study recorded most of the patients seeking orthodontic care for aesthetic reasons.

This present study recorded about $44.3 \%$ of the subjects who had not accepted their malocclusions compared to $49 \%$ in a similar study on tooth loss involving populations from the industrialized parts of the world. ${ }^{25}$ In that very study ${ }^{25} 46 \%$ accepted their tooth loss immediately compared to $28.5 \%$ in this Nigerian study on malocclusion. The following are factors that may influence attitudes towards oral health: age, sex, social class, cultural, regional and national variables. ${ }^{12}$ This present study did not investigate all these factors, but the different age groups, social and cultural climates, and nations involved in the study of Fiske et al. ${ }^{12}$ and this Nigerian study could account for the differences. In addition the expected loss of teeth with age in their study unlike the unexpected obvious deviations of dental arrangements or appearances in the Nigerian study population could further account for the relatively low acceptance of malocclusion among the Nigerians.

The same pattern of results observed in the study of Fiske et al. ${ }^{12}$ and this present Nigerian study in relation to acceptance of occlusal anomalies is maintained in regard to effects on confidence level of the subjects (patients). Thirty-seven percent of the people reported feeling less confident as a result of tooth loss compared to $44.3 \%$ in this Nigerian study. According to Heldt et al. ${ }^{31}$ patients with dentofacial deformities, regardless of severity, are frequently the victims of ridicule, teasing, and jokes; the emotional trauma being evident in interviews with patients victimized by this abuse.

The present Nigerian study has shown over half $(54.8 \%)$ of the subjects believed their malocclusions affected their facial appearances generally. According to Shaw ${ }^{32}$ about 200 investigations conducted over the last decade did demonstrate ubiquitous effect of facial attractiveness in many social settings. These include friendship, dating and marriage choice, scholastic assessments, helping behavior, criminal identification, and simulated court setting. Unexpected obvious deviations of dental arrangements or appearances in this Nigerian study population could further account for the relatively low acceptance of malocclusion among the Nigerians. Recently Kerosuo et al. ${ }^{33}$ showed poor dento-facial appearance produces negative perceptions of personal characteristics.

The same pattern of results in the acceptance of occlusal anomaly and that of Fiske et al. ${ }^{12}$ was observed in the confidence level of the subjects (patients). Thirty-seven percent of the people reported feeling less confident as a result of tooth loss compared to $44.3 \%$ in this Nigerian study. The present Nigerian study also observed considerable restriction of normal activities among the study sample due to their malocclusions. Optimum oral health, among other things, should 
include a socially acceptable smile and dentofacial profile. ${ }^{34}$ In fact health, as currently viewed, involves the ability of an individual to perform daily activities including social and emotional well being and quality of life. ${ }^{35,36}$

Although parental orthodontic awareness in Nigeria is still relatively $\operatorname{low}^{28}$, the present study shows they (parents) will remain very crucial in the utilization of orthodontic care in the country as a majority of the subjects discussed their worries with them. The important role of parents in the motivation for orthodontic care has been demonstrated in other reports. ${ }^{2,37,38}$

\section{Conclusion}

This clinical study has shown considerable psychosocial or emotional effects of malocclusion on Nigerian orthodontic patients, which should be considered during professional counseling and treatment of such patients in order to improve their self-esteem and social interactions.

\section{References}

1. Helm S, Kreiborg S, Solow B. Malocclusion at adolescence related to self-reported tooth loss and functional disorders in adulthood. Am J Orthod. 1984 85(5) : 393-400.

2. Jenny J. A social perspective on need and demand for orthodontic treatment. Int Dent J. 1975 25: 248-256.

3. Stricker G. Psychological issues pertaining to malocclusion. Am J Orthod. 1970 58: 276-283.

4. Gochman DS. The measurement and development of dentally relevant motives. J Public Health Dent. 1975 35: 160-164.

5. Tedesco LA, Albino JE, Cunat JJ, et. al. A dental-facial attractiveness scale. Part 1. Reliability and validity. Am J Orthod. 1983 83(1): 38-43.

6. Shaw WC, Rees G, Dawe M, et. al. The influence of dentofacial appearance on the social attractiveness of young adults. Am J Orthod. 1985 87(1): 21-26.

7. Burns MH. Psychological aspects of orthodontics. In: Cinnotti WR, Grieder A, Springob HK.(eds). Applied Psychology in dentistry. pp 200-208. St Louis: C.V. Mosby, 1972.

8. MacGregor F. Social and psychological implications of dentofacial disfigurement. Angle Orthod. 1970 40:231-233.

9. Silverman M. Orthodontics and body-image. Pa Dent J (Harrisb). 1971 Nov;38(8):10-5. No abstract available.

10. Weiss J. Body image in orthodontics. J N J State Dent Soc. 1973 Fall;45(1):14-7. No abstract available.

11. Jensen SH. The psychological dimensions of oral and maxillofacial surgery: a critical review of the literature. J Oral Surg. 1978 36:447-453.

12. Shaw WC, Addy M, Ray C. Dental and social effects of malocclusion and effectiveness of orthodontic treatment. A review. Community Dent. Oral Epidemiol. 1980 8:36-45.

13. Klima RJ, Witteman JK, Mclver JE. Body image, self-concept and the orthodontic patient. Am J Orthod. 1979 75: 507-515.

14. Sergal HG, Stodt W. Experimental investigation of the aesthetic effect of various tooth positions after loss of an incisor tooth. Eur Orthod Soc. Trans. 1970; 497-507.

15. Aloia GF. Effects of physical stigmata and labels on judgments of subnormality by preservice teachers. Ment Retard. 1975 13: 17-21.

16. Clifford MM. Physical attractiveness and academic performance. Child Stud J. 1975 5: 201-209.

17. Rich J. Effects of children's physical attractiveness on teachers' evaluations. J Educ Res. 1975 67: 599-609.

18. Cavior N, Dokecki PR. Physical athractireness, perceived attitude similarity and academic achievement as contributors to interpersonal attraction among adolescents. Develop Psychol. 1973 9: 44-54.

19. Dion KK. The incentive value of physical attractiveness for young children. Pers Soc Psychol Bull. 1977 3: 167-170. 
20. Kleck RE, Richardson SA, Ronald L. Physical appearance cues and interpersonal attraction in children, Child Develop. 1974; 45: 305-310.

21. Lowenstein LR. The bullied and non-bullied child. Bull Br Psychol Soc. 1978 31:316-318. 22. Adams GR. Physical attractiveness research: toward a developmental Psychology of beauty. Human Develop. 1977 20:217-239.

23. Berschied E. An overview of the psychological affects of physical attractiveness. In: Luckier GW, Ribbens KA, McNamara JA. (eds.). Psychological aspects of form. Ann Arbor, MI: Center for Human Growth and Development, 1-23.

24. Jenny J, Proshek JM. Visibility and prestige of occupations and the importance of dental appearance. Canad Dent J. 1986 52:987-989.

25. Fiske J, Davis DM, Leung KCM, et. al. The emotional effects of tooth loss in partially dentate people attending prosthodontic clinics in dental schools in England, Scotland and Hong Kong: A Preliminary Investigation. Int Dent J. 2001 51: 457-461.

26. Gosney MBE. An investigation into some of the factors influencing the desire for orthodontic treatment. Br J Orthod. 1986 13: 87-94.

27. Shaw WC. Factors influencing the desire for orthodontic treatment. Eur J Orthod. 1981 3: 151-162.

28. Onyeaso CO. Orthodontic concern of parents compared with orthodontic treatment need assessed by Dental Aesthetic Index (DAI) in Ibadan, Nigeria. Odontostomatol Trop Mar. 2003 107:14-20.

29. Onyeaso CO, Arowojolu MO. Perceived, desired, and normatively determined orthodontic treatment needs among orthodontically untreated Nigerian adolescents. West Afri J Med. Jan-Mar 2003 22(1): 5-9.

30. Ingervall B, Hedegard B. Awareness of malocclusion and desire of orthodontic treatment in 18-yearold Swedish men. Acta Odontol Scand. 1974 32:93-101.

31. Heldt L, Haffke EA, Davis LF. The psychological and social aspects of orthognathic treatment. Am J Orthod. 198282 (4):318-328.

32. Shaw WC. The influence of children's dentofacial appearance on their attractiveness as judged by peers and lay adults. Am J Orthod. 1981 79(4): 399-415.

33. Kerosuo N, Hausen $\mathrm{H}$, Laine $\mathrm{T}$, et. al. The influence of incisal malocclusion on the social attractiveness of young adults in Finland. Eur J Orthod. 1995 17: 505-512.

34. Feng XP, Newton JT, Robinson PG. The impact of dental appearance on perceptions of personal characteristics among Chinese people in the United Kingdom. Int Dent J. 2001 15: 282-286.

35. World Health Organization. The Constitution of the World Health Organization. WHO Chronicle 1.29, Geneva: World Health Organization, 1947.

36. Reisine ST. Theoretical considerations in formulating sociodental indicators. Soc Sci Med. 1981 15: 743-750.

37. Lewit DW, Virolainen K. Conformity and independence in adolescents' motivation for orthodontic treatment. Child Develop. 1968; 39: 189-200.

38. Mechanic D. Ideology and Medical technology and health are organization in modern nations. Am J Public Health. 1974 65: 241-247. 


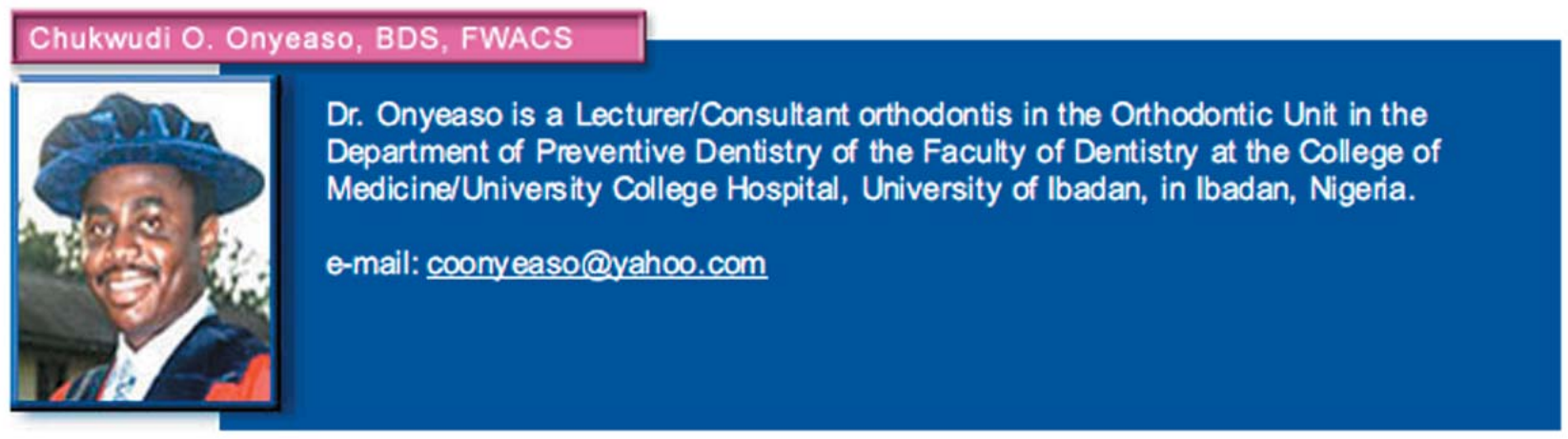

\section{Ifeoma L. Utomi, BDS, FWACS}

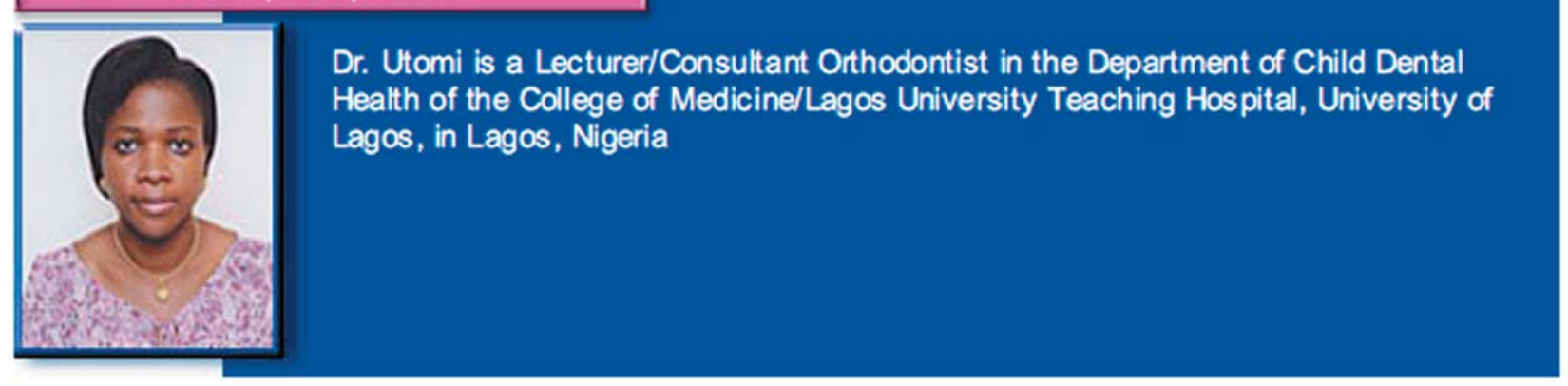

\section{Titus S. Ibekwe, MBBS}

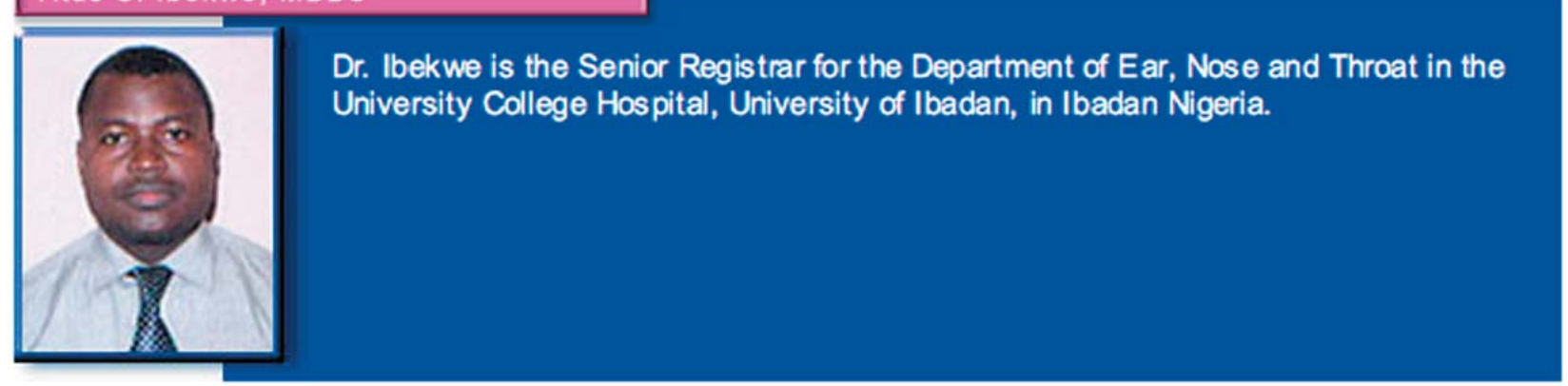

